\title{
Clinical and Affective Correlates of Cognitive Functioning in Complicated Mild and Moderate Traumatic Brain Injury Patients Belonging to Rural Areas
}

\author{
Akanksha Chaurasiya ${ }^{1}$ Jay Kumar Ranjan ${ }^{1}$ Nityanand Pandey² Hari Shanker Asthana ${ }^{1}$ \\ ${ }^{1}$ Department of Psychology, Faculty of Social Sciences, \\ Banaras Hindu University, Varanasi, Uttar Pradesh, India \\ 2Department of Neurosurgery, Institute of Medical Sciences, \\ Banaras Hindu University, Varanasi, Uttar Pradesh, India \\ Address for correspondence Nityanand Pandey, MCh, \\ Department of Neurosurgery, Institute of Medical Sciences, \\ Banaras Hindu University, Varanasi, 221005, Uttar Pradesh, India \\ (e-mail: nityanand_pandey@yahoo.co.in).
}

\begin{abstract}
Background/Objective Mild and moderate traumatic brain injury (TBI) is a neglected field especially with reference to its association with cognitive, behavioral, and emotional sequelae. The present study aimed to investigate the association of affective symptoms and clinical factors with neurocognitive functioning in complicated mild and moderate TBI patients.

Materials and Methods The sample comprised 39 complicated mild and moderate TBI patients with age range of 18 to 59 years. The study was conducted in the Department of Neurosurgery, Banaras Hindu University, Varanasi. The patients were assessed with the neurocognitive tests, Rivermead Post Concussion Symptom Questionnaire, and Hospital Anxiety and Depression Scale.

Statistical Analysis Partial correlations and zero order correlations were used to test the relationships between variables.

Keywords

Results The injury-related factors, namely level of consciousness and Glasgow Coma

- traumatic brain injury

- head injury

- neurocognitive

- psychological distress

- symptoms

- anxiety

- depression

- impairment

- rural Scale were found to be associated with divided attention and memory dysfunction $(p<0.05)$, respectively. Anxiety was found to be associated with impairment on all domains of neurocognitive function $(p<0.05)$ except divided attention. Depressive symptoms were found to be correlated with all the neurocognitive functions $(p<0.05)$ except focused and divided attention, whereas head injury symptoms correlated with impairment on focused and divided attention $(p<0.05)$.

Conclusion Present study highlights the need to acknowledge affective symptoms along with clinical factors in the planning of the rehabilitation programs for such patients in rural scenario.
\end{abstract}

\section{Introduction}

Traumatic brain injury (TBI) is a major cause of death and disability. The neurocognitive, somatic, and emotional sequelae after TBI become a challenge not only to healthcare system but also for the families of the patients. ${ }^{1}$

DOI https://doi.org/ $10.1055 / \mathrm{s}-0040-1715083$ ISSN 0976-3147.
A substantial number of TBI survivors have suffered from complicated mild and moderate TBI. ${ }^{1}$ Disturbances in higher cerebral functions due to injury comprised the disintegration of cognition as well as emotion that impact on recovery. ${ }^{2}$ Thus, it might be essential to assess the association of clinical and affective component with neurocognitive functions to get
(C) 2020. Association for Helping Neurosurgical Sick People.

This is an open access article published by Thieme under the terms of the Creative Commons Attribution-NonDerivative-NonCommercial-License, permitting copying and reproduction so long as the original work is given appropriate credit. Contents may not be used for commercial purposes, or adapted, remixed, transformed or built upon. (https://creativecommons.org/licenses/by-nc-nd/4.0/)

Thieme Medical and Scientific Publishers Pvt. Ltd., A-12, 2nd Floor, Sector 2, Noida-201301 UP, India 
an accurate picture of post-TBI outcome. To date, few studies attempt to find out the correlates of neurocognitive functions in TBI patients and reported contradictory results. ${ }^{3-6}$ In the study on TBI patients, it was found that affective symptoms affect attentional task requiring simple processing ${ }^{5,6}$ whereas impact of injury-related factors is reflected in complex, flexibility demanding tasks. ${ }^{7}$

Head injury symptoms often follow mild TBI; thus, most of researches on head injury symptoms have been conducted on patients with mild TBI. ${ }^{8}$ However, it has been recommended to assess the nature of head injury symptoms in cases with relatively more severe brain injury. ${ }^{8}$

It is quite evident that nature of neurocognitive task and domain of cognitive function is quite different across studies. Furthermore, there is dearth of studies assessing the correlation of affective sequelae with neurocognitive function in complicated mild and moderate TBI patients in Indian scenario ${ }^{9}$ specifically in rural context. It is indicated in the literature that patients from rural area suffer from a poorer outcome. ${ }^{10}$ Therefore, a study on patients belonging to rural areas is of greater need. Thus, the purpose of the study was to assess the relationship between psychological distress, post head injury symptoms, and neurocognitive impairment in patients with complicated mild and moderate TBI.

\section{Methods}

\section{Participants}

It is a comparative, cohort study conducted at Neurosurgery Department of Sir Sunderlal Hospital and Trauma Centre, BHU. Thirty-nine complicated mild and moderate TBI patients with age range of 18 to 59 years and educated up to eighth grade were selected for the study by using purposive sampling technique. Complicated mild TBI had a Glasgow Coma Scale (GCS) score between 13 and 15, along with a radiological evidence of cerebral bleeding/abnormality. Patients with moderate TBI had GCS score between 9 and 12. Patients who were able to read and comprehend Hindi language properly were included in the study. Patients who scored below 4 on digit span task were classified as having poor effort ${ }^{11}$ and those patients were not included in the study. Patients with any major impairment in verbal communication, audibility, visualization, motor coordination, or physical amputation after injury were excluded. Further, patients having history of previous psychiatric disorder, head trauma were excluded from the study. Written informed consent was obtained from patients to participate in the study.

\section{Tools}

Neurocognitive assessment of patients was done using several subtests of NIMHANS battery, namely Digit Symbol Substitution Test (DSST) for mental processing speed, Controlled Oral Word Association Test (COWAT) for phonemic fluency, and Stroop test for response inhibition. ${ }^{12}$ Further, AIIMS memory scale for memory ${ }^{13}$ and Trail Making Test (TMT) for visual search speed and mental flexibility ${ }^{14}$ were used. The psychological distress was assessed with Hospital Anxiety and Depression Scale (HADS). ${ }^{15}$ A score of $\geq 8$ on a subtest indicates psychological distress on that affective component, that is, anxiety and depression. ${ }^{15}$ The post head injury symptoms were assessed with the Rivermead Post Concussion Symptoms Questionnaire (RPCSQ). ${ }^{16}$ Rating of $\geq 2$ on any symptom indicates that the symptoms in problematic range. Furthermore, patient having four or more symptoms on this questionnaire were classified as having post head injury symptoms in clinical range. ${ }^{16}$

\section{Procedure}

Data collection took place between August, 2018 and May, 2019. Participants were selected as per preset inclusion and exclusion criteria. After rapport establishment, clinical and demographical details were recorded and informed consent was obtained from the participants. After that neuropsychological tests, HADS, and RPCSQ were administered and scored according to the standardized procedure. All the protocols of the study were followed in accordance with the Helsinki Declaration. The relationships of neurocognitive impairment with post head injury symptoms, GCS, and psychological distress were tested, by using partial correlations and zero order correlations.

\section{Results}

The sociodemographic and clinical characteristics of patients are presented in - Table 1. Mean age of patients was 29.46 years. From the 39 participants, 29 (74.4\%) were males and 10 (25.6\%) were females. Nineteen patients (48.7\%) were single and 10 (25.6\%) were married. Education level of most of the participants was graduation (48.7\%). At the time of hospital admission, 17 patients had a GCS score of more

Table 1 Clinical and demographic characteristics of TBI patients

\begin{tabular}{|l|l|l|}
\hline \multirow{2}{*}{ Gender } & & $\begin{array}{l}\text { TBI patients } \\
(\boldsymbol{n}=39)\end{array}$ \\
\hline \multirow{2}{*}{ Age (in years) } & Male & $29(74.4 \%)$ \\
\cline { 2 - 3 } & Female & $10(25.6 \%)$ \\
\hline \multirow{2}{*}{$\begin{array}{l}\text { Employment } \\
\text { status }\end{array}$} & Single & $29.46 \pm 9.56$ \\
\cline { 2 - 3 } & Married & $19(48.7 \%)$ \\
\cline { 2 - 3 } & Student & $20(51.3 \%)$ \\
\cline { 2 - 3 } & Home-maker & $17(43.6 \%)$ \\
\hline \multirow{3}{*}{ Education } & Primary-middle & $14(35.9 \%)$ \\
\cline { 2 - 3 } & Higher secondary & $8(20.5 \%)$ \\
\cline { 2 - 3 } & UG+ & $10(25.6 \%)$ \\
\hline \multirow{2}{*}{$\begin{array}{l}\text { GCS at the time } \\
\text { of arrival }\end{array}$} & Moderate TBI (GCS: 9-12) & $17(43.60 \%)$ \\
\cline { 2 - 3 } & $\begin{array}{l}\text { Complicated mild TBI } \\
\text { (GCS:13-15) }\end{array}$ & $22(56.40 \%)$ \\
\hline \multirow{2}{*}{$\begin{array}{l}\text { Loss of } \\
\text { consciousness }\end{array}$} & Present & $24(61.5 \%)$ \\
\cline { 2 - 3 } & Absent & $15(38.5 \%)$ \\
\hline
\end{tabular}

Abbreviations: GCS, Glasgow Coma Scale; SD, standard deviation; TBI, traumatic brain injury; UG, undergraduate. 
than 8 but below 13. Twenty-four patients presented with the history of loss of consciousness at the time of admission (-Table 1).

-Figure 1 depicts that in the neurocognitive domain; most of the patients were found impaired on processing speed (66.7\%). In affective domain, 9 (23.1\%) patients were found anxious, 11 (28.2\%) with depressive symptoms, and $14(35.9 \%)$ having head injury symptoms in problematic range.

The results depicted in - Table 2 indicate that there was a moderate positive correlation between reaction time in performing divided attention task and presence of level of consciousness (LOC) while controlling anxiety $\left(r^{(36)}=0.321\right.$, $p<0.05$ ).

Similarly, a positive correlation was found between memory dysfunction and LOC while controlling anxiety $\left(r^{(36)}=0.361, p<0.05\right)$. However, zero order correlation showed that there was a statistically significant positive correlation between memory dysfunction and $\operatorname{LOC}\left(r^{(37)}=0.319, p<0.05\right)$. It can be inferred that anxiety had a very little influence in controlling the relationship between memory dysfunction and LOC (-Table 2).

Furthermore, a significant negative correlation was found between GCS score and reaction time in divided attentional task $\left(r^{(37)}=-0.353, p<0.05\right)$. It indicates that patients with higher GCS score have taken lesser time in performing the divided attention task. The relationship remains significant while controlling depression $\left(r^{(36)}=-0.324\right.$, $p<0.05)$ and anxiety $\left(r^{(36)}=-0.320, p<0.05\right)$, whereas controlling head injury symptom has decreased the association $\left(r^{(36)}=-0.256, p>0.05\right)$. In this line, the bivariate correlation between memory dysfunction and GCS $\left(r^{(37)}=-0.333\right.$, $p<0.05)$ was found to be nonsignificant while controlling anxiety $\left(r^{(36)}=0.296, p>0.05\right)$, depression $\left(r^{(36)}=-0.275\right.$, $p>0.05)$, and head injury symptom $\left(r^{(36)}=-0.299, p>0.05\right)$ (-Table 2).

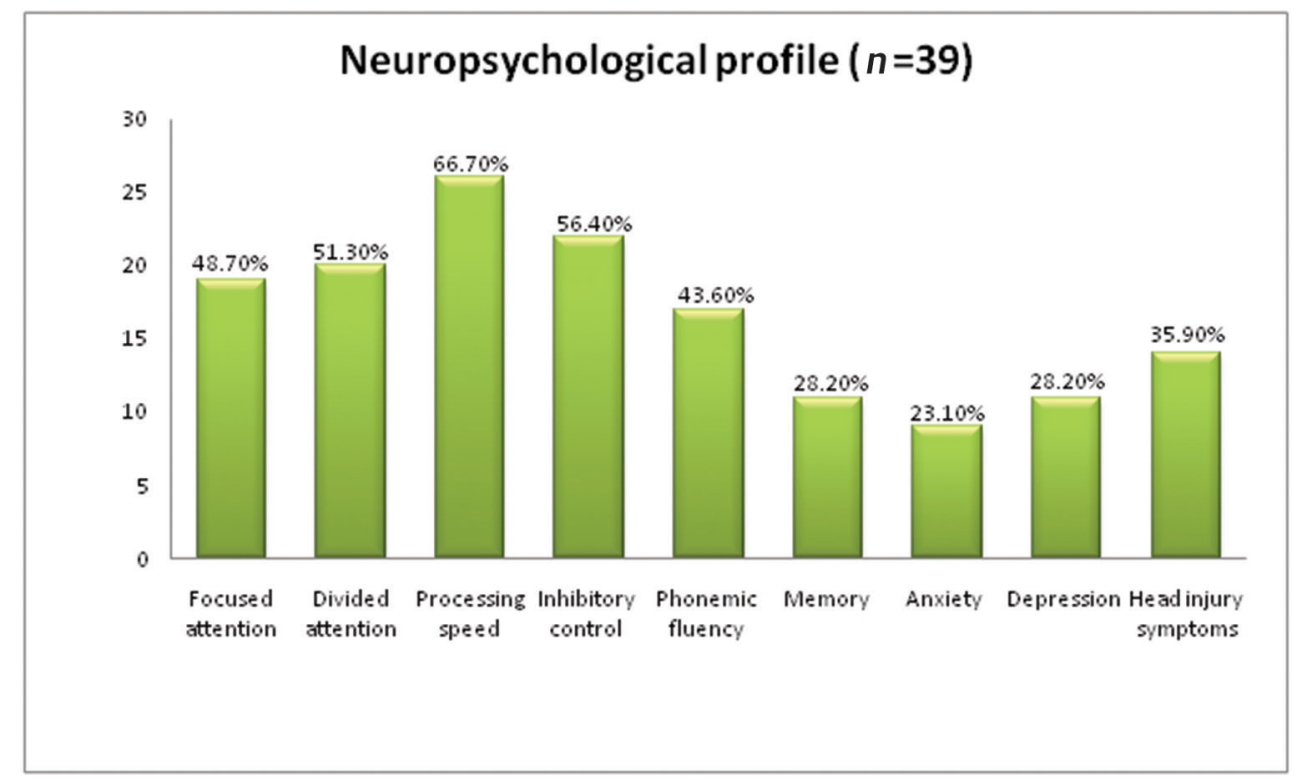

Fig. 1 Neuropsychological profile of patients $(n=39)$.

Table 2 Clinical correlates of cognitive functioning in patients with TBI

\begin{tabular}{|l|l|l|l|l|l|l|l|l|}
\hline & \multicolumn{3}{|c|}{ LOC } & \multicolumn{4}{c|}{ GCS } \\
\hline & Bivariate $r^{\mathrm{a}}$ & Partial $r^{\mathrm{b}}$ & Partial $r^{\mathrm{c}}$ & Partial $r^{\mathrm{d}}$ & Bivariate $r^{\mathrm{a}}$ & Partial $r^{\mathrm{b}}$ & Partial $r^{\mathrm{c}}$ & Partial $r^{\mathrm{d}}$ \\
\hline Focused attention & 0.030 & 0.052 & 0.012 & 0.034 & 0.099 & 0.043 & 0.074 & 0.010 \\
\hline Divided attention & 0.289 & $0.321^{*}$ & 0.269 & 0.244 & $0.353^{*}$ & $0.320^{*}$ & $0.324^{*}$ & 0.256 \\
\hline Processing speed & 0.134 & 0.177 & 0.088 & 0.095 & 0.169 & 0.105 & 0.098 & 0.101 \\
\hline Phonemic fluency & 0.014 & 0.053 & 0.049 & 0.046 & 0.259 & 0.201 & 0.195 & 0.178 \\
\hline Inhibitory control & 0.104 & 0.131 & 0.064 & 0.055 & 0.246 & 0.203 & 0.194 & 0.169 \\
\hline Memory & $0.319^{*}$ & $0.361^{*}$ & 0.292 & 0.298 & $0.333^{*}$ & 0.296 & 0.275 & 0.299 \\
\hline
\end{tabular}

Abbreviations: GCS, Glasgow Coma Scale; LOC, level of consciousness; TBI, traumatic brain injury.

aBivariate unadjusted correlations of each neurocognitive functions with LOC and GCS.

bPartial correlations of each neurocognitive functions with LOC and GCS adjusted for anxiety.

cPartial correlations of each neurocognitive functions with LOC and GCS adjusted for depressive symptoms.

dPartial correlations of each neurocognitive functions with LOC and GCS adjusted for post head injury symptoms.

"Significant at 0.05 level.

"Significant at 0.01 level. 
In regard to affective symptoms, a significant positive association of anxiety was seen with focused attention $\left(r^{(37)}=0.354, p<0.05\right)$, processing speed $\left(r^{(37)}=0.455\right.$, $p<0.01)$, inhibitory control $\left(r^{(37)}=0.351, p<0.05\right)$, and memory dysfunction $\left(r^{(37)}=0.356, p<0.05\right)$ (-Table 3 ). It indicates that the patients with higher scores of anxiety have higher reaction time in performing focused attention, processing speed, and inhibitory control tasks. They also scored higher on task assessing memory dysfunction. These correlations were still significant while controlling for LOC and GCS. On the other hand, the association between divided attention and anxiety was found significant while controlling LOC $\left(r^{(36)}=0.344, p<0.05\right)$. Furthermore, significant moderate negative correlation was found between anxiety and phonemic fluency $\left(r^{(37)}=-0.575, p<0.01\right)$. It shows that patients with higher score on anxiety have produced lesser words in phonemic fluency task. Similarly, depressive symptoms were found to be correlated with processing speed, phonemic fluency, inhibitory control and memory in zero order correlation, as well as while controlling LOC and GCS (see - Table 3). It implies that clinical factors have little influence on controlling the relationship between neurocognitive function and psychological distress.

- Table 3 illustrates a significant moderate positive correlation of post head injury symptoms with focused $\left(r^{(37)}=0.377, p<0.05\right)$ and divided attention $\left(r^{(37)}=0.482\right.$, $p<0.01)$. It shows that patients with higher score on head injury symptom severity have higher reaction time in performing TMT-A (focused attention) and TMT-B (divided attention) tasks. The relationships remain significant while controlling for GCS and LOC. In addition, post head injury symptom severity score was found to be associated with phonemic fluency $\left(r^{(37)}=-0.348, p<0.05\right)$ and the association remained significant while controlling for LOC $\left(r^{(36)}=-0.351\right.$, $p<0.05)$ but not while controlling for GCS $\left(r^{(36)}=-0.296\right.$, $p<0.05)$. Furthermore, the bivariate correlation between inhibitory control and head injury symptom $\left(r^{(37)}=0.328\right.$, $p<0.05)$ dropped while controlling for LOC $\left(r^{(36)}=0.317\right.$, $p>0.05)$ and for GCS $\left(r^{(36)}=0.277, p>0.05\right)$. It signifies the effect of LOC and GCS in the association between inhibitory control and post head injury symptom.

\section{Discussion}

In present study, substantial number of patients with complicated mild and moderate TBI had deficits on mental speed, inhibitory control, and divided attention and patients also suffer from psychological distress and post head injury symptoms. Literature pertains that brain injury exerts damages that alter the network of brain which leads to impairment of these functions and that lead to symptoms. ${ }^{17}$

The present study pertains that affective sequelae were associated with various neurocognitive functions whereas injury related factors were found to be correlating with only divided attention and memory function. It has been reported in previous studies that neurocognitive outcome in patients with complicated mild TBI is quite similar to that of moderate TBI. ${ }^{7,18,19}$ The crude categorization of GCS and LOC might be a parsimonious reason that injury severity-related indicators were found to be correlated with a few neurocognitive functions in patients with complicated mild and moderate TBI.7,18,19

Present study has demonstrated the association of psychological distress with neurocognitive functions in patients with complicated mild and moderate TBI. Literature suggests that slowed information processing and neurocognitive impairment lead to psychological distress. ${ }^{5}$ To compensate for cognitive impairment, additional mental effort is required to perform everyday tasks, which results in greater psychological distress in TBI patients. ${ }^{5}$ Furthermore, the psychological distress results in an attentional bias toward external stimuli and distraction by internal intrusive, ruminative, and worrisome thoughts. It leads to impaired performance on neurocognitive task.

Furthermore, current study indicates that head injury symptoms correlate with impairment on attentional task. Literature pertains that patients with post head injury symptoms have to divide their attention between these symptomatic thoughts and demand of attentional task. It

Table 3 Affective correlates of cognitive functioning in patients with TBI $(n=39)$

\begin{tabular}{|c|c|c|c|c|c|c|c|c|c|}
\hline & \multicolumn{3}{|c|}{ Anxiety } & \multicolumn{3}{|c|}{ Depression } & \multicolumn{3}{|c|}{ Head injury symptoms } \\
\hline & $\begin{array}{l}\text { Bivariate } \\
r^{\mathrm{a}}\end{array}$ & Partial $r^{b}$ & Partial $r^{c}$ & $\begin{array}{l}\text { Bivariate } \\
r^{\mathrm{a}}\end{array}$ & Partial $r^{b}$ & Partial $r^{c}$ & $\begin{array}{l}\text { Bivariate } \\
r^{\mathrm{a}}\end{array}$ & Partial $r^{b}$ & Partial $r^{c}$ \\
\hline Focused attention & $0.354^{*}$ & $0.356^{*}$ & $0.344^{*}$ & 0.138 & 0.135 & 0.121 & $0.377^{*}$ & $0.367^{*}$ & $0.365^{*}$ \\
\hline Divided attention & 0.314 & $0.344^{*}$ & 0.276 & 0.210 & 0.180 & 0.151 & $0.482^{* *}$ & $0.460 * *$ & $0.424^{* *}$ \\
\hline Processing speed & $0.455^{* *}$ & $0.467 * *$ & $0.439^{*}$ & $0.402^{*}$ & $0.391^{*}$ & $0.381^{*}$ & 0.265 & 0.249 & 0.229 \\
\hline Phonemic fluency & $0.575^{* *}$ & $0.576^{* *}$ & $0.558^{* *}$ & $0.431^{* *}$ & $0.433^{* *}$ & $0.400^{*}$ & $0.348^{*}$ & $0.351^{*}$ & 0.296 \\
\hline Inhibitory control & $0.351^{*}$ & $0.358^{*}$ & $0.323^{*}$ & $0.332^{*}$ & $0.322^{*}$ & 0.297 & $0.328^{*}$ & 0.317 & 0.277 \\
\hline Memory & $0.356^{*}$ & $0.394^{*}$ & $0.323^{*}$ & $0.474^{* *}$ & $0.460 * *$ & $0.441^{* *}$ & 0.181 & 0.139 & 0.095 \\
\hline
\end{tabular}

Abbreviations: LOC, loss of consciousness; GCS, Glasgow Coma Scale; TBI, traumatic brain injury.

aBivariate unadjusted correlations of each neurocognitive functions with anxiety, depressive, and post head injury symptoms.

bPartial correlations of each neurocognitive functions with anxiety, depressive, and post head injury symptoms adjusted for LOC.

'Partial correlations of each neurocognitive functions with anxiety, depressive, and post head injury symptoms adjusted for GCS.

*Significant at 0.05 level.

** Significant at 0.01 level. 
leads to problems in concentration and impedes performance of several tasks simultaneously. ${ }^{20}$

The study gives insight that for reducing long-term sequelae, only clinical factors should not be the major criteria for designing rehabilitation. However, this is the preliminary study to assess the association between neurocognitive function and affective symptoms in patients with complicated mild and moderate TBI. The findings of the study must be interpreted with the caveat of the small sample size of this subgroup. There is a need for a prospective longitudinal study to investigate the clinical and affective correlates in cognitive recovery.

In conclusion, the impairment in higher order cognitive function and presence of affective symptoms are common and salient characteristics in patients with complicated mild and moderate TBI. The present study signifies the affective symptomatic correlates with cognitive functioning. Therefore, holistic rehabilitation would be appropriate choice for these patients.

\section{Note}

The data collection and procedure of the study was in accordance with Helsinki Declaration.

\section{Funding}

None.

\section{Conflict of Interest}

None declared.

\section{References}

1 Riggio S. Traumatic brain injury and its neurobehavioral sequelae. Neurol Clin 2011;29(1):35-47, vii

2 Prigatano GP. Principles of Neuropsychological Rehabilitation. New York Oxford University Press; 1999

3 Reddy RP, Rajeswaran J, Devi BI, Kandavel T. Cascade of traumatic brain injury: a correlational study of cognition, postconcussion symptoms, and quality of life. Indian J Psychol Med 2017;39(1):32-39

4 Donders J, Stout J. The influence of cognitive reserve on recovery from traumatic brain injury. Arch Clin Neuropsychol 2019;34(2):206-213

5 Eysenck MW, Derakshan N, Santos R, Calvo MG. Anxiety and cognitive performance: attentional control theory. Emotion 2007;7(2):336-353
6 Wensing T, Levasseur-Moreau JTA, Fecteau S, Attentional Processing in Traumatic Brain Injury and Posttraumatic Stress Disorder. In: Sadaka F, ed. Traumatic Brain Injury. London: IntechOpen; 2014

7 Kashluba S, Hanks RA, Casey JE, Millis SR. Neuropsychologic and functional outcome after complicated mild traumatic brain injury. Arch Phys Med Rehabil 2008;89(5):904-911

8 McCauley SR, Boake C, Levin HS, Contant CF, Song JX. Postconcussional disorder following mild to moderate traumatic brain injury: anxiety, depression, and social support as risk factors and comorbidities. J Clin Exp Neuropsychol 2001;23(6):792-808

9 Datta SG, Pillai SV, Rao SL, Kovoor JME, Chandramouli BA. Post-concussion syndrome: correlation of neuropsychological deficits, structural lesions on magnetic resonance imaging and symptoms. Neurol India 2009;57(5):594-598

10 Brown JB, Kheng M, Carney NA, Rubiano AM, Puyana JC. Geographical disparity and traumatic brain injury in America: rural areas suffer poorer outcomes. J Neurosci Rural Pract 2019;10(1):10-15

11 Strauss E, Sherman EM, Spreen O, A Compendium of Neuropsychological Tests: Administration, Norms, and Commentary. New York: American Chemical Society; 2006

12 Tripathi R, Kumar JK, Bharath S, Marimuthu $P$, Varghese M. Clinical validity of NIMHANS neuropsychological battery for elderly: A preliminary report. Indian J Psychiatry 2013;55(3):279-282

13 Gupta S, Khandelwal SK, Tandon PN, et al. The development and standardization of comprehensive neuropsychological battery in Hindi (adult form) J Personal Clin Stud 2000;16:75-108

14 Tombaugh TN. Trail making test A and B: normative data stratified by age and education. Arch Clin Neuropsycho 2004;19(2):203-214

15 Zigmond AS, Snaith RP. The hospital anxiety and depression scale. Acta Psychiatr Scand 1983;67(6):361-370

16 King NS, Crawford S, Wenden FJ, Moss NEG, Wade DT. The Rivermead Post Concussion Symptoms Questionnaire: a measure of symptoms commonly experienced after head injury and its reliability. J Neurol 1995;242(9):587-592

17 Mahapatra AK, Kamal R. Textbook of Head Injury.4th edition. New Delhi: CBS Publishers; 2014

18 Williams DH, Levin HS, Eisenberg HM. Mild head injury classification. Neurosurgery 1990;27(3):422-428

19 Lange RT, Brickell TA, French LM, et al. Neuropsychological outcome from uncomplicated mild, complicated mild, and moderate traumatic brain injury in US military personnel. Arch Clin Neuropsychol 2012;27(5):480-494

20 Gould KR, Ponsford JL, Spitz G. Association between cognitive impairments and anxiety disorders following traumatic brain injury. J Clin Exp Neuropsychol 2014;36(1):1-14 